\title{
Our Robotic Future and How we Should React
}

Matt Jones

Computational Foundry

Swansea University

UK

Let me tell you a story, a frightening disturbing one, a story about a future we would never have purposefully set out to create. As this is a scary tale, we need to begin in the dark so close your eyes and picture in your mind's eye the first memory you have of a robot.

What was it? Perhaps, like me, it was a tin wind-up figure like the one pictured in Image 1. In my case, it sparked into life when I hauled it out of the sack Father Christmas left at the foot of my bed on December $25^{\text {th }}$, many, many years ago. I wound it up, released it and saw it teeter unsteadily along my bedroom floor - I was both terrified and delighted.

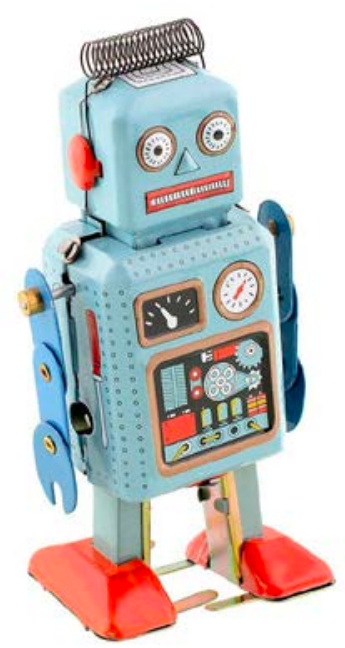

Image 1: Early Memories of a Robotic Future

From our earliest days, be it as a small child receiving a Christmas gift or collectively as societies focussed on technological progress, perhaps we knew a day would come when delight with the possibilities offered by our innovations would turn to fear and despair. The day when robots would take our jobs; the day when jobs we thought robots would do for us, like cleaning and caring for our elderly, were the only ones left for us to do. We knew this day would come when the next stage in the slither-to-walk-to-human evolution would be robots that outclassed and outpaced us; when they, not us would be the most heavenly of creations.

\section{We Build them and then Backlash...}

In movies, books and magazines, the source of this invasion is often portrayed as coming from "outside"; an alien planet that has hyper-advanced technology intent on colonising ours: think the Marvel franchise, Daleks or the Transformers. But the genesis of our downfall was always going to be ourselves: for centuries people have been attempting to 
create automatons. Take Leonardo's $15^{\text {th }}$ Century proposal for a robot knight in amour; or, jump forward to the $20^{\text {th }}$ Century to another armoured humanoid, when the organisers of a conference made an automated replacement for the invited speaker, the King of England, who had failed to show. If even the Monarch's place can be replaced by machinery, what hope for your job or mine?

Perhaps one of the most famous examples of the fascination with creating new forms of sentient, autonomous life is Mary' Shelly's Frankenstein (interestingly, recently reimagined for the Al-generation by Jenatte Winterson as Frankissstein.) The story illustrates what happens to creations people don't understand, distrust or that frighten them. For Frankenstein's monster, then, instead of acceptance, the response to this new life form was violently negative. In the famous 1950 movie of the book, this is captured by a scene where the crowd comes at night with blazing torches to attack and destroy it.

The current darkness descending on the digital, as people worry about Al and big-data is the first sign of us taking up pitchforks and torches to chase out a technology we have created. How will these future life-forms react to this sort of reception? Perhaps, they will point to first page of Shelly's book:

"Did I request thee, Maker, from my clay to mould me Man, did I solicit thee from Darkness to Promote Me?" (Milton's Paradise Lost).

In other words, if we rise up to try and chase out future Als and robots, might they not justifiably remind us that we created them?

\section{Empower and Be Overpowered}

While we are thinking about creations and creators, let's consider two other "creation" stories to help us think about our Al and robotic destiny. Turn first to Greek mythology and to the demi-God, Prometheus. Picture him tied to a mountain top, receiving terrifying punishment from the Gods. Each day, birds would swoop down to pick painfully with surgical precision at his liver, that agony relived day after day as each night it regrew.

What could he have done to anger the Gods so much to receive such punishment? His sin was to give humankind the power of fire, a technology that enabled them to tame nature, expand their horizons, create tools and with all this, the ability to rely on themselves rather than God. In a TV interview, Stephen Fry muses whether there will be a modern day Prometheus who empowers Als to such an extent they no longer need us:

"Will the Prometheus who makes the first piece of really impressive robotic Al - like Frankenstein or the Prometheus back in the Greek myth - have the question: do we give it fire?

Do we give these creatures self-knowledge, self-consciousness? An autonomy that is greater than any other machine has ever had and would be similar to ours? In other words: shall we be Zeus and deny them fire because we are afraid of them? Because they will destroy us? 
The Greeks, and the human beings, did destroy the gods. They no longer needed them. And it is very possible that we will create a race of sapient beings who will not need us." [Ref 1]

Now consider the Biblical account of the Garden of Eden. Adam and Eve were created by God to live with him in the paradise of Eden. One day, they were tempted to eat of the tree of the knowledge of good and evil, with the devil encouraging them, saying that by eating it they, "...will be like God". Some developers are creating modern-day Adam and Eve's, built to dwell with us in the paradise of our technologically advanced homes, offices or hospitals. But perhaps like the first Adam and Eve, these social robots will seek to become increasingly like us and then leave us, focussed on their own self-determination.

\section{Surely, things can't be this bad?}

With this talk of the Bible and the like you may be writing me off as a street corner prophetof-doom shrilly predicting the "end of the world is nigh". You might be thinking that I'm exaggerating the concerns: will robots really rise up? Will they really want to become better than us? How will they master what we humans have taken millennia to evolve? Will we need to take up pitchforks and torches to chase them out of town?

After all, we've always hyper-ventilated over technological progress only to see things turn out in more happy, mundane, benign ways. So, the scary looking humanoid cleaner robots that were seen in consumer exhibitions in the 1950s turned out to be sleek, subtle and silent Roombas. The Frankenstein-like movie monsters have been replaced by cutesy looking Wall-E robots and there's even a robotic pillow that you can hug to send you to sleep (see Image 2).
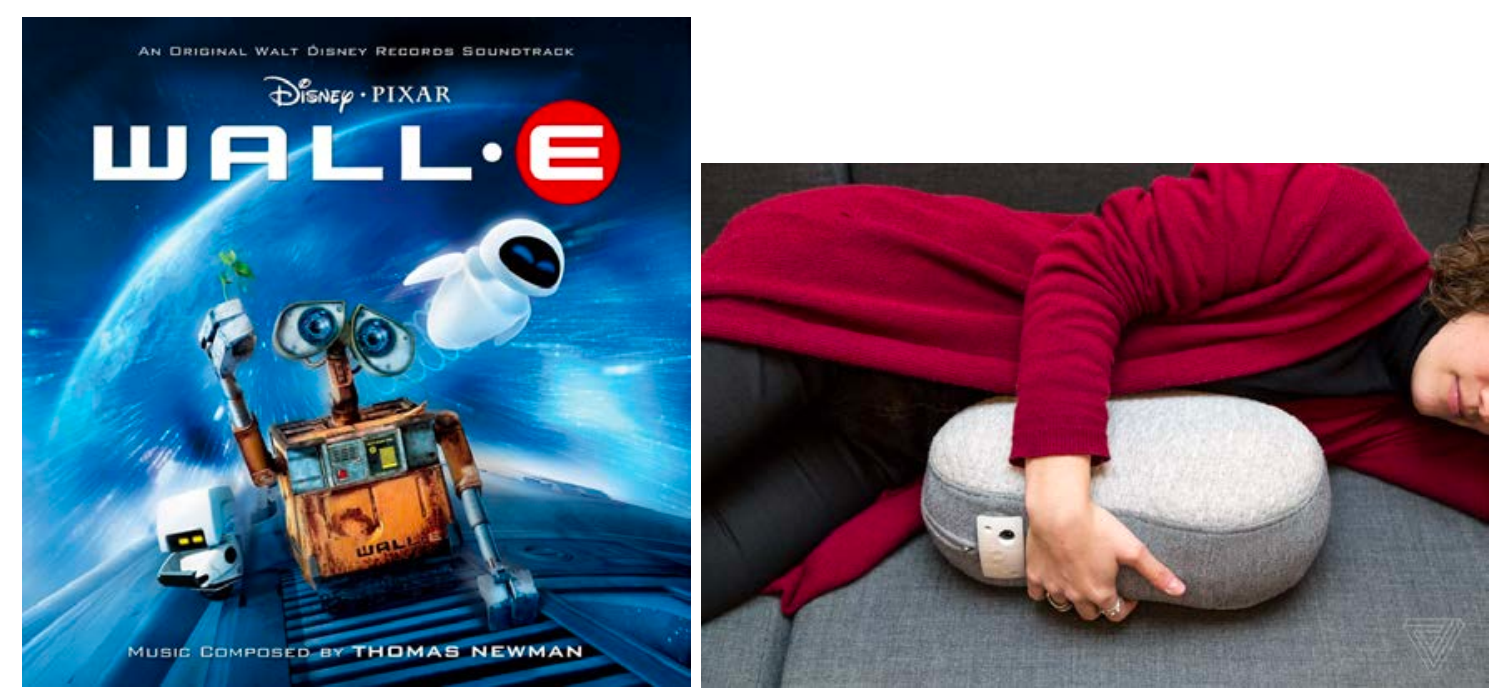

Image 2: Surely nothing to fear here? Wall-E (Left) is a far cry from Frankenstein's monster; and, robots will even soothe us to sleep (right).

So perhaps we can - nestled up to one of the pillows - relax and sleep easily?

\section{Things are Worse than we Thought}


Not quite yet.

Cut to another scary image, this time of a customer, emerging from a tech store, the newest mobile phone in hand. He holds it aloft, his eyes raised to the heavens. It looks like he is on drugs; and he is, and so are we. Enchanted by the devices that offer us endless interactions, entertainment, connection and creativity.

Much has been written over the last several years of how these devices are turning us all into modern day Narcissus's, staring down into the dark pools of our sleek mobile devices, oblivious to those around us who love and care for us. You'll no doubt have experienced many situations where you are sitting with friends and family at a restaurant, meeting or even on a sports field while they peer down and prod the dead glass screen.

While there's much debate about the actual impact on our well-being of such behaviours, its undoubtedly the case that many people are worried about what these technologies are doing to themselves and those around them. Unlike earlier "moral panics" around technology, those worrying include the next generation - for example in CNN survey in $2017,54 \%$ of children worried that their parents spent too much time on their mobile devices [ref 2].

Human Computer Interaction from its inception focussed on how to ensure devices and services fitted human needs. It appears now, though, that a lot of design practice is serving a different agenda: how to get humans to fit the needs of, and become part of, the system. The earliest step in this direction came from B.J Fogg with his Persuasive Technology book (subtitled, "Using Computers to Change What we Think and Do" [Ref 3]) but is now seen ubiquitously within mobile apps and services in the form of gamification (think Instagram Streaks); instant gratification (e.g. micro-rewards); personalisation and the integration of social networks across content. The aim of such design strategies is to sell us more things; shape our thinking and beliefs; to turn us into worker bee drones providing click-by-click data, a far cry from the utopian hope of the wisdom of the crowds.

\section{We are becoming the Robots}

When I was a kid, one of the scariest robot forms were the Cybermen in the TV series Dr Who. Humans were gruesomely transformed into these machines in a process involving chainsaws, with their original flesh and bones co-opted bit-by-bit into a metallic form. The final step of the conversion came as the human's emotional abilities were extracted, leaving them deadened and unempathetic. As we stare down into our mobile devices are we becoming fused into the metallic forms of our mobiles, click-by-click, only too late realising that we are becoming the robots?

While the Cybermen frightened me, there's an even scarier picture you can find by googling, "Mark Zuckerberg VR crowd". You'll see an image of a seated throng all wearing VR headsets their eyes blanked by the devices strapped to their faces. If that's not concerning enough, the juxtaposition of a smiling, unencumbered Zuckerberg walking purposefully down the aisle adds to the discomfort. We have become the robots, enslaved to provide data, value and money to a powerful few. 


\section{Taking Action}

It's not too late and now is the time to act; so what can we do? We might read previous manifestos that argue for better technologies - there's the one produced by the Luddites in the $19^{\text {th }}$ Century that argues for the destruction of technologies that cause humans harm; then, for the digital era, Jaron Lanier has written "You are Not a Gadget", detailing the ways technology might be reframed in human terms [Ref 4].

As a start, I'd like to suggest four ways forward:

-Promote and practice digital detox \& design for digital well being -Design out tempting trivial interactions \& make tech less obtrusive/ more sharable -Amplify what it is to be human

- Get a new perspective from people who are still more human than robot

\section{Promote and practice digital detox \& design for digital well being}

If you haven't tried a digital detox, l'd recommend it as a way of comparing your sense of well-being before and after. You'll find you feel more, not less, connected to what matters if you follow these sorts of simple steps:

- "Delete all social media apps from your phone; check these only from a desktop computer.

- Turn all banner-style/pop-up/sound notifications off all other apps (keep the badgetype notifications where you have to visually check the app).

- Leave your phone in your pocket or keep it out of sight for meetings/gettogethers/conversations/meals involving other people.

- Keep your phone out of sight during your commute.

- Don't take your phone with you into the bathroom or toilet." [Ref 5]

If you are an app designer or developer you can help others too. For inspiration, experiment with the dashboards launched last year by both Apple and Google to help users understand and moderate use of their mobiles. If you want to be more creative, consider designing in a way that draws on what our bodies do if we abuse them: so, what happens if you spend too long in the sun? Your body gets hot and eventually burns, warning you to cover up; or if you overeat, you begin to feel full, then bloated, then sick. What might be the interaction design equivalents?

\section{Design out tempting trivial interactions \& make tech less obtrusive/ more sharable}

When I was growing up the only phone in the house was a landline that sat in the hallway, silent until its bells rang loudly for an incoming call. When it rang, we paid attention with whoever was closest, answering its cry, as automatically as a parent tends to a new-born babe. Someone was making an effort to contact us so we attended. These days, all of our apps, services and even mobile sites seem to want to grab our attention continually, with notifications mushrooming. While users can moderate notifications via both device and app 
settings, there is scope for more nuanced (and less cumbersome) ways to reduce trivial distractions. So, for example, instead of notifying whenever someone retweets why not learn what the user wants, perhaps only bringing it to their attention when many people have liked what they have posted?

Smartwatches have been heralded as one form of mobile that is less obtrusive, although there is some evidence that it drives people greater interactions by being more at-hand than a mobile in the pocket or bag. But one of the nice things about watches that might have been overlooked in the new digital era is that they facilitate physical social interaction. Think about the times you have asked a stranger or been asked by a stranger for the time. (see Image 3a). Inspired by this, in our work, we have looked at making Smartwatch displays that benefit both observer and the wearer (see Image 3b). Our thinking was to use the watch to draw us together, rather than to promote retreat into automaton states.

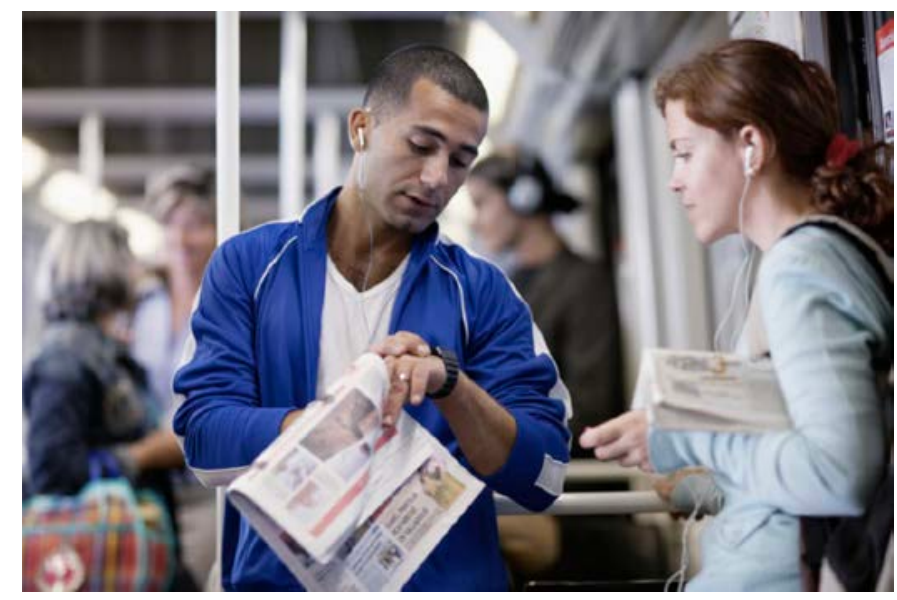

Fig 3a. Some technology like conventional watches keeps us human
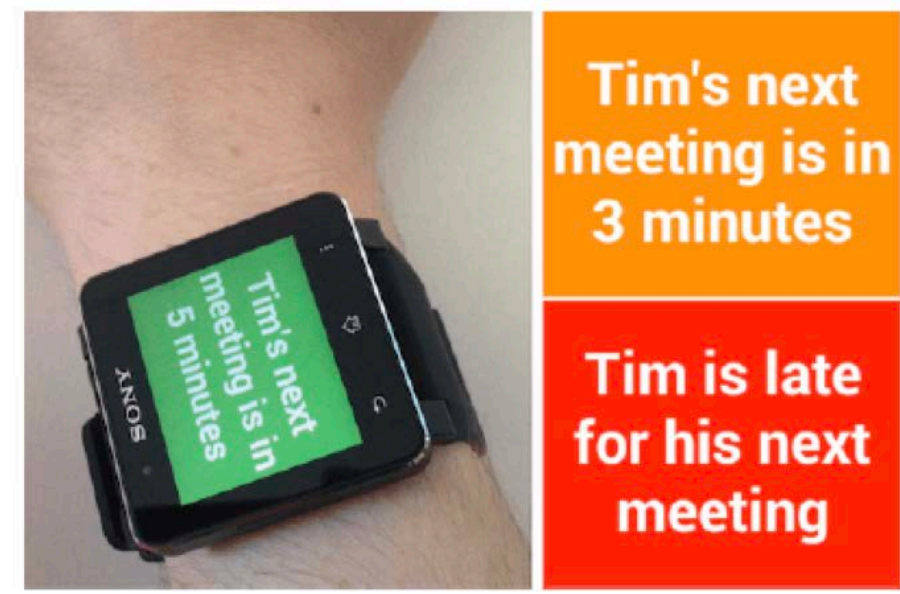

Fig 3b. Using smartwatches to act as a public display. In this case to show the wearer's (Tim) companion information about upcoming meetings [Ref 6].

\section{Amplify what it is to be human}

Every morning (when I am in Swansea) I do two things that really remind me that I am flesh and bones and far more than the robot I might become as I get further drawn to the dark screen of my mobile (see Image 4). As I cycle through the beautiful coastal dawn and then 
later slice through the pool, I use the bike and water as media to express and experience in ways that go far deeper than any current computing device or service can enable. In a similar vein Kia Hook has written beautifully of her experiences with horse-riding, encouraging us to create relationships with technology that are more like it, allowing us to become less cyborg or cyberman in form and more a natural blending of human and tech, or in her words, centaur-like [Ref 7].
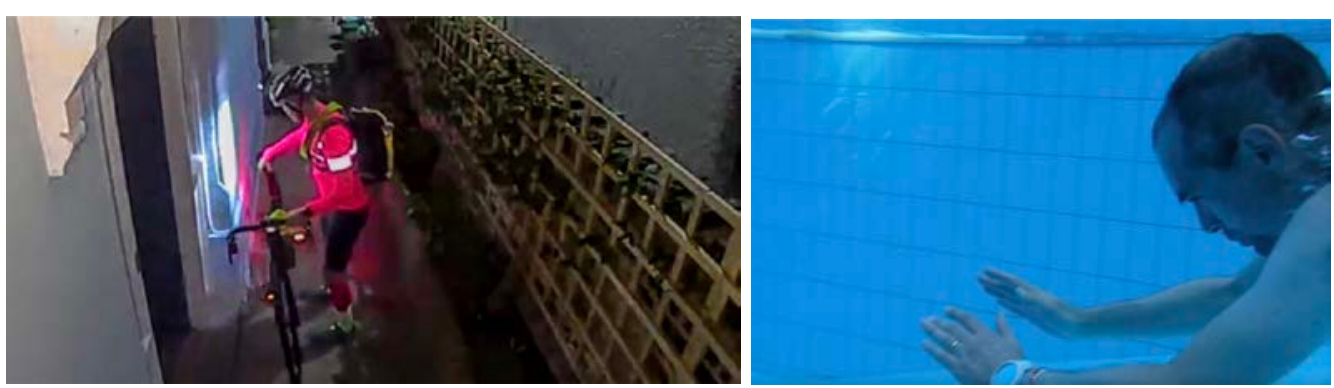

Figure 4: Being alive - how can we learn from highly physical activities to design technology that amplifies what we are rather than deadening us by the digtal.

\section{Get a new perspective from people who are still more human than robot}

For the last five years or so, our team has had the privilege of working with communities and individuals who - unlike most reading this - are only just getting their hands onto digital technology. Many of us will have a mobile phone, perhaps a laptop or a tablet, possibly a Smart TV, home networking and so on; but, for what have been called "emergent users" the mobile smartphone is their first exposure to digital devices and services.

These users inhabit contexts and have a range of constraints and abilities that are quite distinct from "conventional" users like you and me. Typically, they possess lower levels of educational attainment (impacting, for instance textual literacy); have limited income; reliable grid power is not guaranteed; and, personal living space can be much constrained. If you look at the back of many current devices you'll see the words, "designed in California": in engaging with these new user groups we are getting very fresh and challenging, un-Californian views on possible digital futures.

As an example, consider Al voice assistants - like Alexa and Google Home. We have been experimenting with putting adapted versions of these devices into the streets of Dharavi, a large informal settlement in downtown Mumbai, India (See Fig 5 below). In particular we have been comparing the performance of boxes powered only by Al with those that enable answers to be given by people via the cloud. 


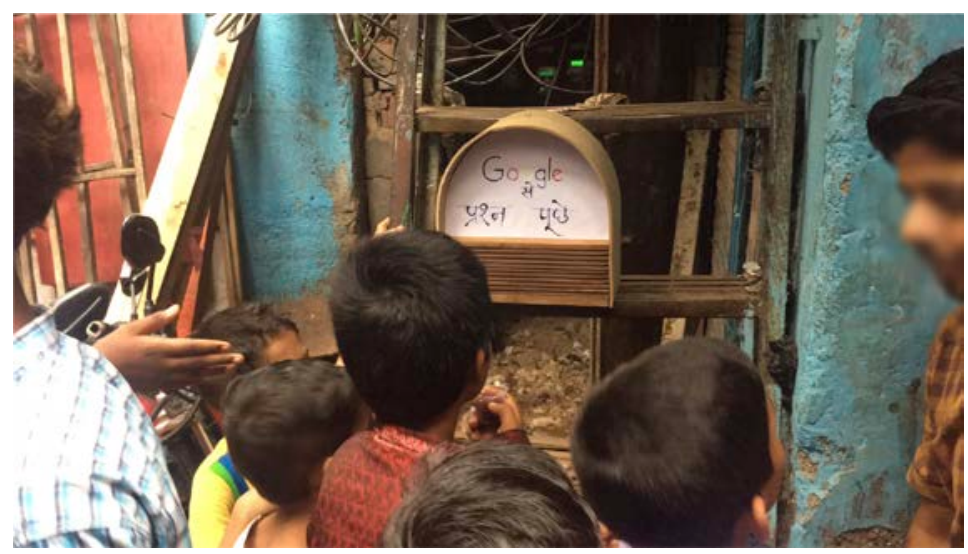

Figure 5: Experimenting with Al and Human-Powered Speech Assistants in Dharavi [Ref 8].

We've learnt a lot from these deployments: one thing that stands out is that there are many questions the Al struggles with - sometimes this is because of speech recognition issues or lack of local context. However, other times the failure is because the $\mathrm{Al}$ is an alien: not human, not of us.

\section{If an Al or Robot Could Speak...}

In a blog post, Richard Harper points to Wittgenstein's book, "If a Lion Could Talk We Could Not Understand Him". The argument is that even if a Lion and human could converse then because they come from completely different worlds, there would not be any meaningful conversations [ref 9].

If the current hype over Al recedes, maybe we will see more clearly that we will never have deep, meaningful interactions with machines even if we can "converse" with them. However, I am scared that something else might happen. The only way we and Al will be able to truly understand each other, is if we become like them, if we become robots, shaped by our continuous interactions on our mobiles.

\section{Two Visions}

To end, lets picture two images of future robots. One, then is the familiar humoid-like device. I caution that worrying about what these technologies will or won't do for and to humanity is a distraction. The other image is of a young baby, prodding, heads-down a tablet computer (if you can't picture it, simply search online for "baby mobile phone"). Rather than being adorable and cute, this sight should wake us from our own digitally induced click-by-click hypnosis to act before the next generation becomes what we have always feared, but in ways we couldn't imagine.

\section{Acknowledgements}

This article is based on a talk I first gave at MUM 2018 in Cairo and then later in Finland for Culumus 2019 - many thanks for the organsiers giving me the impetus to think in new ways. If you want to read more of the suggestions for designing for humans rather than robots, expanded examples are giving in the book I co-authored with Simon Robinson and Gary 
Marsden (There's not An App for That, Morgan Kaufmann). Much of the work mentioned has been funded by the UKs EPSRC.

References

1.

https://youtu.be/9HdmXFXp6yU

2.

https://edition.cnn.com/2017/11/30/health/smartphone-addiction-study/index.html

3.

Fogg, B. J. (2002). Persuasive Technology: Using Computers to Change What We Think and Do (Interactive Technologies)

4.

Lanier, J. (2011). You Are Not a Gadget: A Manifesto

5.

https://www.theguardian.com/technology/2018/jan/13/how-to-quit-your-tech-phonedigital-detox

6. J. Pearson, S. Robinson, M. Jones, "It's About Time: Smartwatches as Public Displays" Proceedings of CHI 2015, Seoul, April 2015.

7. Kristina Höök. 2010. Transferring qualities from horseback riding to design.

In Proceedings of the 6th Nordic Conference on Human-Computer Interaction: Extending Boundaries (NordiCHI '10). ACM, New York, NY, USA, 226-235.

DOI=http://dx.doi.org/10.1145/1868914.1868943

8. Jennifer Pearson, Simon Robinson, Thomas Reitmaier, Matt Jones, Shashank Ahire, Anirudha Joshi, Deepak Sahoo, Nimish Maravi, and Bhakti Bhikne. 2019. StreetWise: Smart Speakers vs Human Help in Public Slum Settings. In Proceedings of the $2019 \mathrm{CHI}$ Conference on Human Factors in Computing Systems (CHI '19). ACM, New York, NY, USA, Paper 96, 13 pages. DOI: https://doi.org/10.1145/3290605.3300326

9. https://profharper.wordpress.com/ 